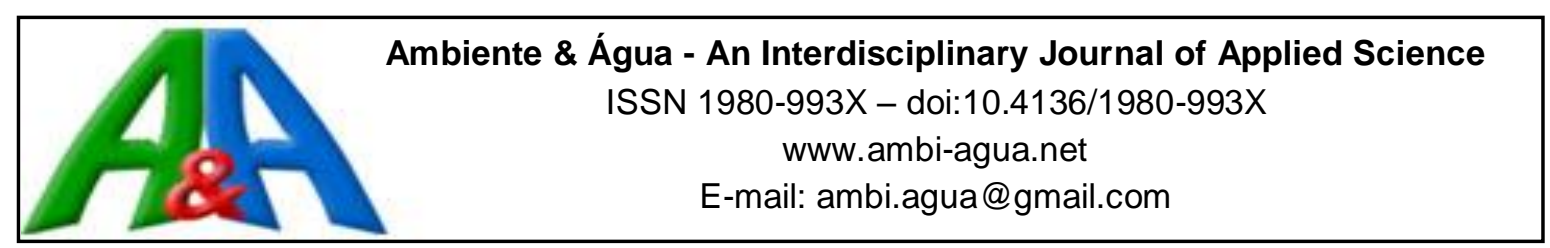

\title{
Barragens de detenção em bacia hidrográfica com o uso de curvas cota-volume e hidrogramas triangulares sintéticos
}

\author{
doi:10.4136/ambi-agua.1900
}

Received: 02 Oct. 2016; Accepted: 02 Nov. 2016

\author{
Paulo José Maria Filho' ${ }^{1}$; Marcelo dos Santos Targa ${ }^{1 *}$; \\ Paulo Sérgio Santos ${ }^{1}$; Nazareno Mostarda Neto ${ }^{1}$ \\ ${ }^{1}$ Universidade de Taubaté (UNITAU), Taubaté, SP, Brasil \\ Programa de Pós-Graduação em Ciências Ambientais \\ *Autor correspondente: e-mail: targa.marcelo@gmail.com, \\ profpauloj@hotmail.com, engpaulosantos18@gmail.com, \\ mostardaneto21@gmail.com
}

\section{RESUMO}

O presente estudo objetivou a aplicação de uma proposta de controle de inundação, por meio da utilização de barramentos para detenção do escoamento superficial, na Bacia hidrográfica do ribeirão do Itaim, em Taubaté, SP. A bacia foi dividida de montante para jusante em 4 trechos delimitando dessa forma as sub-bacias A, B, C e D. Para cálculo da vazão máxima de entrada de água na bacia, em que se adotou a chuva máxima com 100 anos de tempo de retorno e duração igual ao tempo de concentração, foi utilizada a metodologia I-PAI-Wu com a obtenção do coeficiente de escoamento volumétrico C2 por meio do método Curva Número. Para a verificação da cota de inundação foi observada a metodologia hidrograma triangular sintético e a curva cota-volume. Os coeficientes de escoamento (C) obtidos pelo método Curva Número apresentaram valores de 0,$24 ; 0,18 ; 0,24 ; 0,32$ e 0,34 respectivamente para a bacia do Itaim e para as sub-bacias A, B, C e D. Esses valores são menores do que os recomendados pelo DAEE-SP. As áreas e cotas de inundação foram mapeadas e o resultado revelou que a ponte sobre o ribeirão Itaim seria inundada com lâmina de 0,5 metros a partir de uma chuva máxima de 100 anos. Por outro lado, ao se construir os barramentos (A, B, C e D) no limite das sub-bacias, os escoamentos seriam contidos, e a ponte sobre a estrada teria uma folga de cerca de 1,80 metros acima do nível d'água. Esses resultados refletem a capacidade de amortecimento das inundações dos barramentos, pois os escoamentos diminuem com a adoção dessas práticas.

Palavras-chave: bacia, ciências ambientais, escoamento.

\section{Detention dams in hydrographic basin with the use of synthetic triangular hydrograms and volume curves}

\begin{abstract}
This study aimed to apply a flood control proposal, through the use of dams to the runoff of detention for the area of influence of the Itaim stream in Taubaté, Brazil. The basin was divided from upstream to downstream into 4 sections that defined this way, sub- basins $\mathrm{A}, \mathrm{B}$, $\mathrm{C}$ and $\mathrm{D}$. To calculate the maximum inflow of water into the pond we adopted the maximum
\end{abstract}


rainfall with 100 years of time and return time equal to the concentration time using the PAI-I-Wu method to obtain the C2 volume flow coefficient using the curve number method. To verify the level of flooding, a synthetic triangular hydrograph methodology and the quotavolume curve were observed. Flow coefficients (C) obtained by the method of curve number of values of 0.24 showed; $0.18 ; 0.24 ; 0.32$ and 0.34 , respectively, for the Itaim basin and sub basins A, B, C and D. These values are lower than those recommended by DAEE SP. Flood areas and levels were assigned and the result showed that the bridge over the Itaim stream would be flooded from the leaf 0.5 meters of a maximum precipitation of 100 years. On the other hand, in the construction of dams (A, B, C and D) at the edge of the sub-basins, flows would be contained, and the bridge on the highway would have a difference of about 1.80 meters above the D of water. These results reflect the buffer capacity of the flood of buses, because the flows diminish with the adoption of these practices.

Keywords: basin, environmental sciences, outflow.

\section{INTRODUÇÃO}

As alterações no uso e ocupação de solos bem como o crescimento desordenado de municípios modificam as características de escoamento e, por conseguinte podem interferir em processos erosivos, cheias e inundações, os quais devem ser minimizados pela adoção de práticas de conservação da água e do solo.

A detenção do escoamento superficial em bacias hidrográficas pode ser feita por meio de técnicas de detenção do fluxo superficial da água com a utilização de práticas conservacionistas na bacia, tais como o repovoamento florestal de áreas de preservação permanente e reserva legal, adoção de práticas de cultivo mínimo, conservação de solo e água, como a construção de terraços, a adoção de técnicas de infiltração da água captada em telhados, etc. Por outro lado obras do tipo barramento de detenção podem reter a vazão de entrada na bacia e fazer a regulação da vazão de saída em níveis baixos na calha dos cursos d'água. Por outro lado a determinação de cotas de inundação tornou-se um parâmetro obrigatório a ser determinado no licenciamento ambiental de empreendimentos próximos a cursos d'água, devido a exigências específicas da Lei 12.561/2012 (Brasil, 2012), "o novo Código Florestal do Brasil" .

A vegetação florestal total na bacia do Itaim,Taubaté-SP, ocupa aproximadamente 6,47 $\mathrm{km}^{2}$ representando cerca de $11 \%$ da área total da bacia, estando estes últimos remanescentes florestais concentrados na região denominada Serra da Piloa, e em área próximo a nascente do rio Itaim. Na maior parte da bacia há um predomínio da vegetação de campos de pastagens, tanto nas áreas de topo de morro, como também nas várzeas a ao longo de rios, córregos e represas (Calzetta e Targa, 2003).

A rede hidrográfica dessa bacia, estando sobre influência das chuvas de verão, apresenta vazões de pico nos meses chuvosos de dezembro e janeiro. Na maior parte da região, o clima pode ser considerado subtropical quente, com verões chuvosos e invernos secos. A temperatura média anual situa-se acima de $21^{\circ} \mathrm{C}$, sendo a média anual de umidade relativa do ar superior a $70 \%$ (Targa et. al., 2006).

Segundo Calzetta e Targa (2003) na bacia do Itaim encontram-se vários agentes impactantes, como rodovias, ferrovia, aeroporto, gasoduto, linhas de transmissão de energia elétrica, aterro sanitário, monocultura, projetos urbanísticos (lotes residenciais).

O escoamento superficial na bacia do ribeirão Itaim aumentou no período de 2003 para 2010 em função das mudanças no uso e cobertura do solo para todos os tempos de retorno de chuva analisados, sendo as diferenças maiores para os tempos de retorno maiores. Sendo o Itaim, uma bacia localizada em área de crescimento urbano, deve haver controle na mudança no uso do solo para prevenir aumento da erosão (Melo et al., 2011). 
Em estudos sobre a geração das hidrógrafas unitárias para simular o escoamento superficial para o ano 2020 na bacia do Itaim, em Taubaté-SP consideraram cenário de desenvolvimento concervacionista, concluíram que a adoção de política de conservação para a bacia de atingir em 2020 com zero de solo nu, e um aumento de 352\% na área florestal bem como a manutenção da área de vegetação natural em regeneração nos mesmos patamares de 2003 (Anacleto et al., 2015).

Na definição de sistemas para a retenção do escoamento superficial, dados de vazão local é importante para o estabelecimento dos limites de operação das vazões de saída. Moreira et al. (2006) ajustaram a equação da curva chave do ribeirão Itaim e observaram que a vazão do ribeirão Itaim próximo ao exutório da bacia varia de $0,5 \mathrm{~m}^{3} / \mathrm{s}$ a $1,0 \mathrm{~m}^{3} / \mathrm{s}$ durante a primavera e o verão. Contudo nos casos mais extremos no verão atingiu picos de vazão da ordem de 8,12 $\mathrm{m}^{3} / \mathrm{s}$, que equivale ao nível de água de $2,5 \mathrm{~m}$ e acima do qual o ribeirão Itaim extravasa a sua calha e provoca inundações. Estudos para dimensionamento de sistemas de detenção do escoamento superficial, do tipo, barramento de detenção ou piscinão, caracterizado como reservatório aberto ou fechado com função regular a vazão de saída, de maneira a atenuar os efeitos a jusante, pode contribuir para o entendimento do funcionamento desses sistemas. É importante em estudos dessa natureza utilizar-se de hidrogramas para a quantificação do escoamento em bacias hidrográficas.

Ao avaliar hidrógrafas unitárias na simulação do escoamento na bacia hidrográfica do ribeirão do Itaim em cenário de urbanização sustentável para o ano 2020, a bacia apresentou capacidade de amortecimento das cheias pela cobertura vegetal da bacia, agregadas aos pontos de infiltração de água dos condomínios, projetados com aproximadamente metade da área (Perim et al., 2015).

Dessa forma o presente estudo tem por objetivo verificar a capacidade de retenção de escoamento superficial pelo controle da vazão de saída de barramentos de detenção na bacia do Ribeirão Itaim em Taubaté, SP.

\section{MATERIAIS E MÉTODO}

O presente estudo foi conduzido na bacia hidrográfica do ribeirão Itaim (Figura 1), que possui área de $58,9 \mathrm{~km}^{2}$. O Ribeirão Itaim, têm sua nascente nas coordenadas W $45^{0} 36^{\prime} 28^{\prime \prime}$ e S 2309'46", com sua localização próxima à divisa de Taubaté, com os municípios de Caçapava e Redenção da Serra e seu exutório no rio Una, nas coordenadas W 45 30 '23" e S $23^{\circ} 01$ '28", situada no interior da Fazenda Piloto do Departamento de Ciências Agrárias da Universidade de Taubaté (Corrêa, 2001).

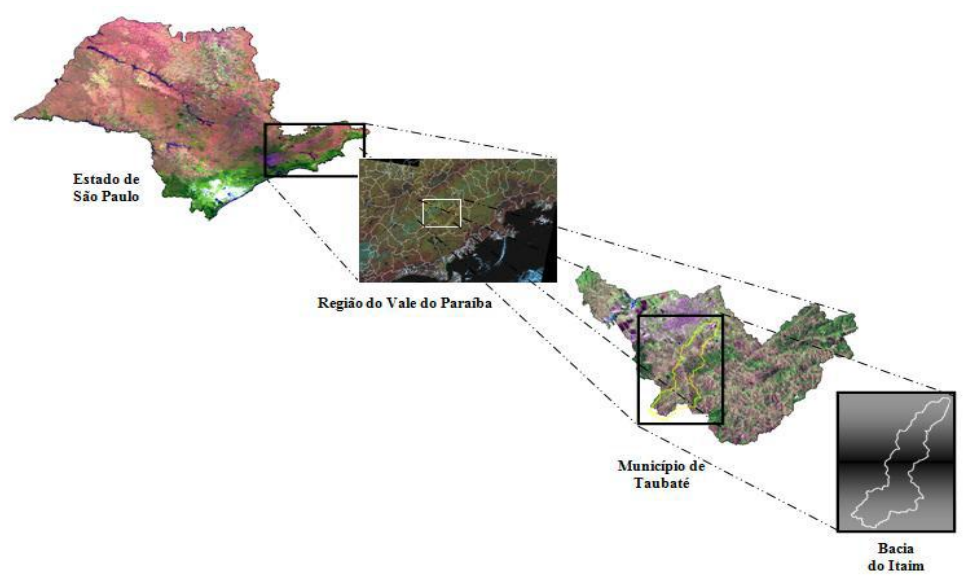

Figura 1. Localização da Bacia do Ribeirão Itaim.

Fonte: Aguiar et al. (2007). 
De acordo com Fisch (1999), o clima da região caracteriza-se por ser quente e úmido no verão, enquanto que no inverno é frio e seco. O total de chuvas no verão, comumente, excede $200 \mathrm{~mm}$, com chuvas quase diariamente no verão. $\mathrm{O}$ ano hidrológico inicia-se em agosto e termina em julho do não seguinte, com $42 \%$ de precipitação ocorrendo nos meses de dezembro a fevereiro, o total da precipitação para o município de Taubaté é de $1.355 \mathrm{~mm}$.

O levantamento dos tipos de solos realizado por Sbruzzi (2004), na bacia do Itaim identificou a ocorrência de solos gleissolo háplico $(\mathrm{Gx})$ nas áreas de várzea no curso baixo do ribeirão, o latossolo vermelho amarelo (LVA), que acompanha os canais fluviais do ribeirão e seus afluentes, e na parte baixa encontra-se lateralmnete e acima das áreas de várzea, o argissolo vermelho amarelo (PVA) abrange principalmente as partes elevadas do curso baixo da bacia e declividades intermediárias nos cursos mais elevados e o cambissolo háplico $\mathrm{Tb}$ distrófico latossólico $(\mathrm{C})$ que abrange da parte média em diante o curso alto da bacia e áreas elevadas.

A bacia do Ribeirão Itaim possui predominantemente pastagens, apresentando solo de baixa e média infiltração. Sua localização está em área considerada de expansão urbana do município de Taubaté e por isso tem sofrido pressão por ocupação humana (Aguiar et al., 2007) e encontra-se em estágio avançado de degradação ocasionado pela pouca vegetação natural existente, pelo baixo nível de conservação dos solos e das estradas, pela criação extensiva de gado bovino, pela existência de processos erosivos e nível de assoreamento dos cursos d'água, conforme já evidenciado em Corrêa (2001) e ainda, com aproximadamente 7\% da bacia apresenta solo exposto, a erosão está presente em todos os tipos de degradação (Lobato e Targa, 2004).

Para a estimativa do escoamento superficial na bacia hidrográfica do Itaim utilizou-se o método Curva Número (CN), do o NRCS, (2010) é baseado nas equações 1 e 2.

$$
\begin{gathered}
P e=\frac{(P-0,2 S)^{2}}{(P+0,8 S)} \\
S=\frac{25000}{C N}-254
\end{gathered}
$$

em que:

Pe $=$ Precipitação efetiva $(\mathrm{mm})$

$\mathrm{P}=$ precipitação máxima em dado período de retorno $(\mathrm{mm})$

$\mathrm{S}=$ Infiltração Potencial (mm)

$\mathrm{CN}=$ Curva Número, adimensional.

O valor do Curva Número $(\mathrm{CN})$ pode ser ponderado em função dos diferentes usos e ocupação (cobertura) do solo da bacia hidrográfica do ribeirão Itaim, (Targa, 2011) por meio da expressão (3):

$$
\text { CNpond }=\frac{\sum\left(C N_{c}\left(A_{c}\right)\right)}{\text { Area }_{t}}
$$

em que:

CNpond $=$ Valor do Curva Número ponderado, adimensional.

$\mathrm{CNc}=$ Valor do curva número de cada classe de uso e cobertura do solo da bacia, adimensional.

Ac = Área de cada classe de uso e cobertura do solo da bacia em ha.

At $=$ Área total da bacia, em ha. 
$\mathrm{O}$ coeficiente de escoamento volumétrico $\mathrm{C}_{2}$ por oportuno pode ser determinado por meio da relação entre $\mathrm{P}$ e Pe, de acordo com equação (4).

$$
C_{2}=\frac{P}{P e}
$$

O Tempo de concentração da bacia (Tc), referido como aquele em que toda precipitação na bacia passa a contribuir para o escoamento foi calculado por meio da equação (5) denominada Kirpich descrita em Tucci (2000).

$$
T c=57 *\left[\frac{L^{2}}{S}\right]^{0,385}
$$

em que:

Tc $=$ tempo de concentração em minutos

$\mathrm{L}=$ comprimento do talvegue $(\mathrm{km})$

$\mathrm{S}=$ Declividade equivalente do curso d'água $(\mathrm{m} / \mathrm{km})$

A precipitação é um dos principais parâmetros utilizados no método Curva Número e, portanto sua definição deve ser baseada preferencialmente em dados locais e provenientes de estudos de intensidade-duração-frequência. O estudo feito para estado de São Paulo, por Martinez Junior e Magni (1999), incluiu o município de Taubaté, SP a partir de dados de 30 anos com interrupções (1964-65; 1969-88; 1990-97). Contudo, os autores conseguiram apresentar uma consistente equação de chuvas intensas (6) para a duração t em minutos definida no intervalo $10 \leq \mathrm{t} \leq 1440$.

$$
\mathrm{i}_{\mathrm{t}, \mathrm{T}}=54,5294(\mathrm{t}+30)^{-0,9637}+11,0319(\mathrm{t}+20)^{-0,9116} \cdot[-0,4740-0,8839 \ln \cdot \ln (\mathrm{T} / \mathrm{T}-1)]
$$

em que:

i: intensidade da chuva, em $\mathrm{mm} / \mathrm{min}$;

t: duração da chuva em minutos;

T: período de retorno em anos

A vazão máxima produzida por uma chuva com 100 anos de Tempo de retorno uniformemente distribuída na bacia do Itaim foi calculada pelo método I-PAI-WU aplicável a

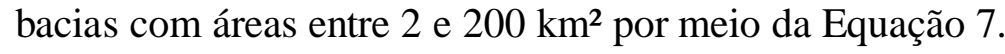

$$
Q=0,278 \times C \times i \times A^{0,9} K
$$

em que:

$\mathrm{Q}=$ vazão em $\left(\mathrm{m}^{3} / \mathrm{s}\right)$

$\mathrm{C}=$ coeficiente de escoamento superficial "run-off"

$\mathrm{i}=$ intensidade da chuva $\mathrm{em} \mathrm{mm} / \mathrm{h}$

$\mathrm{A}=$ área da bacia hidrográfica em $\mathrm{km}^{2}$

$\mathrm{K}=$ coeficiente de distribuição espacial da chuva 
O Coeficiente de escoamento C é calculado pela Equação 8.

$$
C=\frac{2}{1+F} * \frac{C_{2}}{C_{1}}
$$

em que:

$\mathrm{C}=$ coeficiente de escoamento superficial "run-off"

$\mathrm{C}_{2}=$ coeficiente volumétrico de escoamento

$\mathrm{C}_{1}=$ coeficiente de forma.

O Coeficiente de forma $\mathrm{C}_{1}$ é calculado pela Equação 9:

$$
C_{1}=\frac{4}{2+F}
$$

em que:

$\mathrm{C}_{1}=$ coeficiente de forma

$\mathrm{F}=$ Fator de forma da bacia

O Fator de forma F é calculado pela Equação 10.

$$
F=\frac{L}{2(A / \pi)^{0,5}}
$$

em que:

$\mathrm{F}=$ Fator de forma da bacia

$\mathrm{L}=$ talvegue do rio em $\mathrm{km}$

$\mathrm{A}=$ área da bacia em $\mathrm{km}^{2}$

O Coeficiente volumétrico de escoamento $\left(\mathrm{C}_{2}\right)$ depende do grau de impermeabilização da área da bacia e em geral é obtido em recomendações feitas pela literatura especializada, nesse estudo esses coeficientes serão calculados a partir dos estudos de Precipitação efetiva do método Curva Número (USDA, 1997).

$\mathrm{Na}$ definição de sistemas para a retenção do escoamento superficial, dados de vazão local são importantes para o estabelecimento dos limites de operação das vazões de saída. Moreira, et al. (2006) ajustaram a equação da curva chave do ribeirão Itaim (Equação 11) e observaram que a vazão do ribeirão Itaim próximo ao exutório da bacia varia de $0,5 \mathrm{~m}^{3} / \mathrm{s}$ a $1,0 \mathrm{~m} / \mathrm{s}$ durante a primavera e o verão. Contudo, nos casos mais extremos, atingiu picos de vazão da ordem de $8,12 \mathrm{~m} / \mathrm{s}$, o que equivale ao nível de água de $2,5 \mathrm{~m}$ acima do qual o ribeirão Itaim extravasa a sua calha e provoca inundações.

$$
Q=2.86 H^{1,14}
$$

em que:

$\mathrm{Q}=$ vazão do curso d'água $\mathrm{em} \mathrm{m}^{3} / \mathrm{s}$

$\mathrm{H}=$ altura do nivel do curso d'água em $\mathrm{m}$ 
Na definição da área de inundação promovida pelos barramentos de detenção, utilizou-se a metodologia da curva cota-volume (DAEE, 2008) para calcular os Volumes de entrada (Ve) e de saída (Vs) dos barramentos em cada sub-bacia, obtendo-se dessa forma o Volume resultante (Vr) e a cota de inundação. Nessa metodologia os volumes são obtidos a partir da construção de hidrogramas de cheias simplificados em forma triangular e com o uso da equação 12.

$$
V=\frac{Q^{*} T_{b}}{2}
$$

\section{RESULTADOS E DISCUSSÃO}

A partir dos planos cartográficos em escala de 1: 50.000 (IBGE, 1973) e também de imagem Google Earth (2014) foi possível com o uso de ferramentas do ARQ GIS se obter área da bacia e de quatro sub-bacias (A, B, C e D) definidas, de montante para jusante, a partir de sua nascente, bem como o comprimento de cada trecho do ribeirão Itaim, conforme pode ser observado na Figura 2.

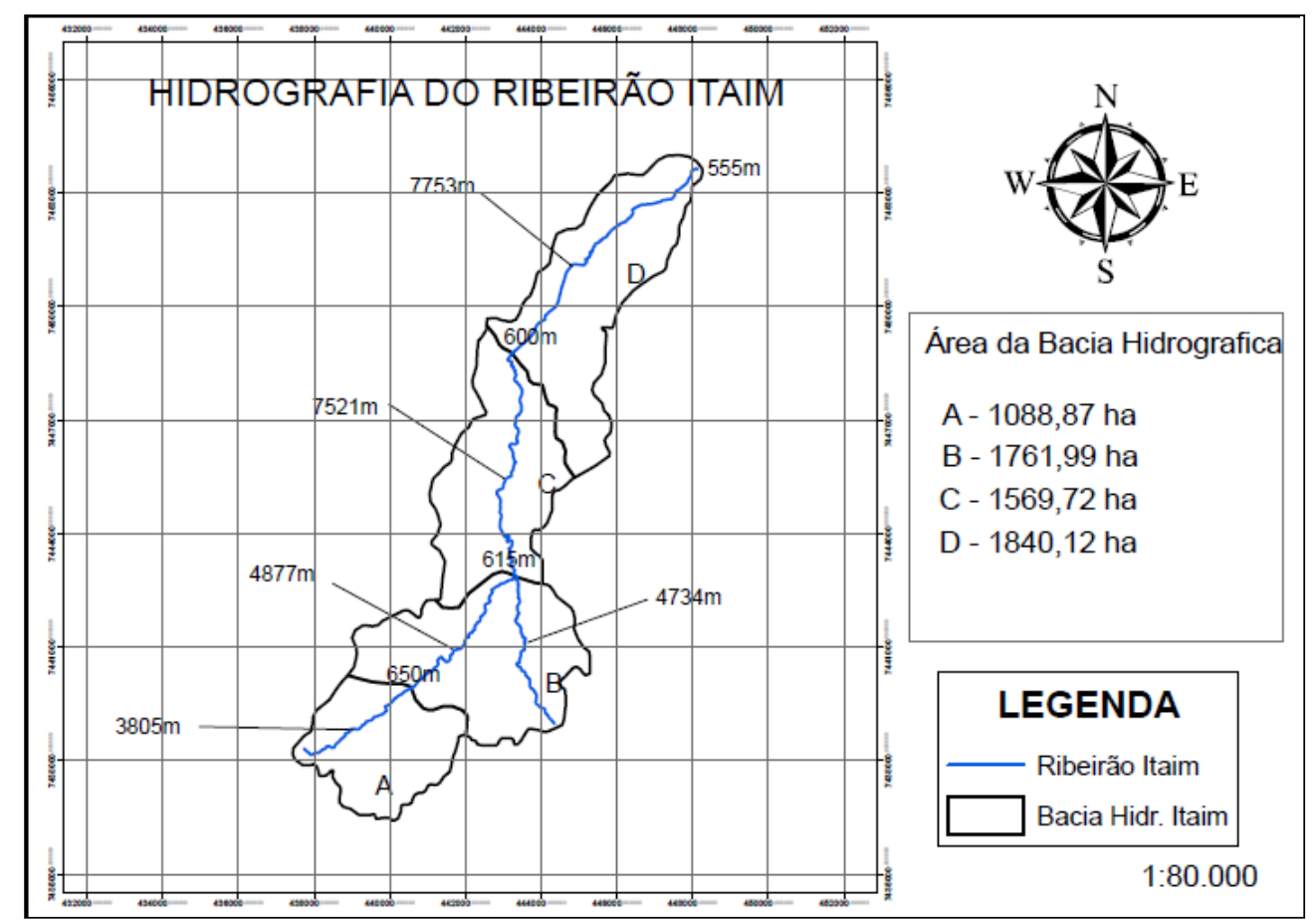

Figura 2. Área da bacia do ribeirão Itaim,Taubaté, SP, com as altitudes e comprimentos do corpo d'água principal em cada sub-bacia.

Com os dados de vazão do ribeirão Itaim Moreira et al. (2006) foi possível observar que as vazões de $0,5 \mathrm{~m}^{3} / \mathrm{s}$ ocorrem em $50 \%$ do tempo e que a de $1,0 \mathrm{~m}^{3} / \mathrm{s}$ ocorrem em $20 \%$ do tempo. Contudo os picos de vazão da ordem de $2,0 \mathrm{~m}^{3} / \mathrm{s}$ a $2,5 \mathrm{~m}^{3} / \mathrm{s}$ ocorrem respectivamente em 3 e $2 \%$ do tempo, mas quando se atinge valores acima de 2,5 de nível a capacidade máxima da calha do ribeirão extravasa, quando atinge ao valor de vazão de $8,12 \mathrm{~m} / \mathrm{s}$, a qual foi utilizada como valor de saída nos barramentos de cada sub bacia.

Com base nos estudos conduzidos por Calzetta e Targa (2003); Lobato e Targa (2004); Targa et al. (2006); Moreira et al. (2006), a bacia hidrográfica do Ribeirão Itaim, apresenta predominância de pastagens, em solos com baixa capacidade de infiltração e com avançados 
estágios de degradação, notadamente de processos erosivos. Caracteriza-se ainda por apresentar $21 \mathrm{~km}$ de comprimento do curso d’água principal e $0,017 \mathrm{~m} / \mathrm{m}$ de declividade média.

A espacialização dos diferentes tipos de solos da bacia (Figura 3) foi realizada com base no levantamento de solos feito por Sbruzzi (2004) e pela utilização dos partir dos planos cartográficos em escala de 1: 50.000 (IBGE, 1977) e também de imagem Google Earth (2014) por meio do uso de ferramentas do ArqGIS.

Com relação a ocorrência de solos na bacia conforme se observa na Figura 3, o Gleissolo háplico $(\mathrm{Gx})$ ocorre nas áreas de várzea no curso baixo do ribeirão Itaim, o Latossolo vermelho amarelo (LVA), acompanha os canais fluviais do ribeirão e seus afluentes, e na parte baixa da bacia encontra-se lateralmente e acima das áreas de várzea. $\mathrm{O}$ Argissolo vermelho amarelo (PVA) abrange principalmente as partes elevadas do curso baixo da bacia e declividades intermediárias nos cursos mais elevados e, por fim, o Cambissolo háplico Tb distrófico latossólico $(\mathrm{C})$ que abrange da parte média em diante o curso alto da bacia e áreas elevadas.

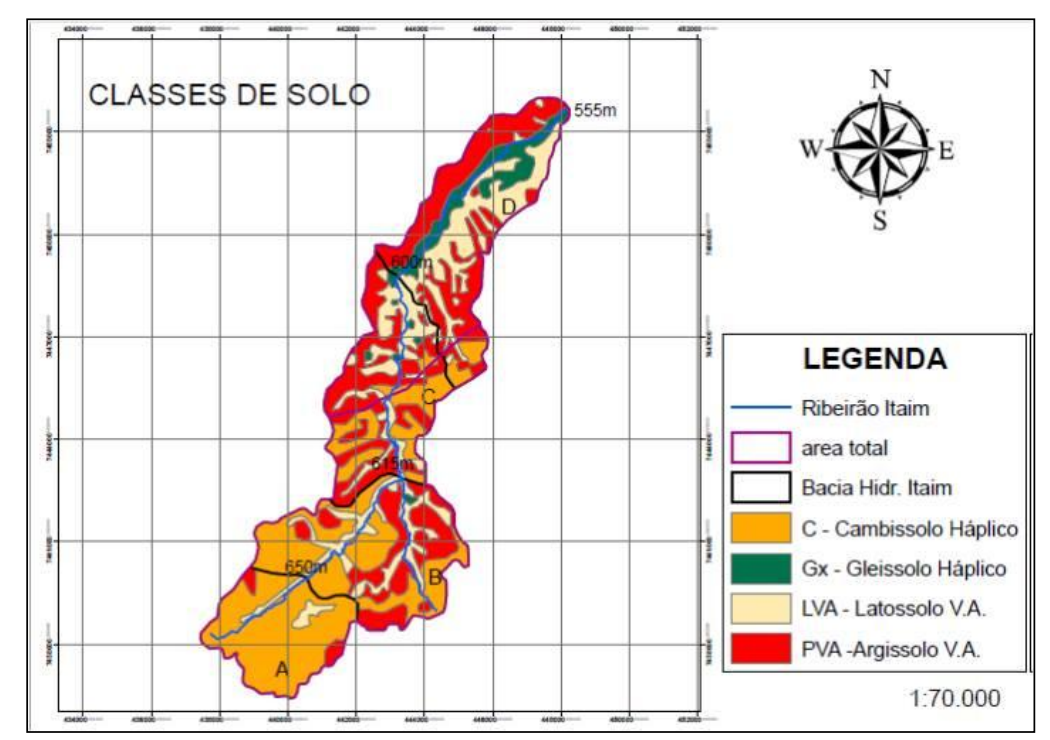

Figura 3. Mapa de tipos de solo na bacia do ribeirão Itaim.

Segundo a classificação hidrológica para solos do Brasil (Sartori et al., 2005), em todas as sub-bacias do Itaim existem solos do tipo hidrológico B, C e D, mas pela distribuição percentual desses solos nas sub-bacias (Tabela 1) observa-se que ocorre predominância de solos do tipo hidrológico C, paras as sub-bacias A, B, C e D, da ordem de 91,22\%, 81,40\%, $76,32 \%$ e $50,90 \%$ respectivamente.

Tabela 1. Áreas totais e percentuais de cada tipo hidrológico de solo para cada subbacia do Ribeirão Itaim.

\begin{tabular}{|c|c|c|c|c|c|c|c|c|}
\hline \multicolumn{9}{|c|}{ Tipos de Solo/Classificação Hidrológica } \\
\hline \multirow{2}{*}{ Sub-Bacia } & \multirow{2}{*}{$\begin{array}{c}\text { Gx / D } \\
\text { (ha) }\end{array}$} & \multicolumn{3}{|c|}{$\mathrm{LVA} / \mathrm{B}$} & \multirow{2}{*}{$\begin{array}{c}\text { PVA / C } \\
\text { (ha) }\end{array}$} & \multicolumn{3}{|c|}{$\mathrm{C} / \mathrm{C}$} \\
\hline & & $\%$ & (ha) & $\%$ & & $\%$ & (ha) & $\%$ \\
\hline A & & & 95,63 & 8,78 & 21,37 & 1,96 & 971,87 & 89,25 \\
\hline B & 8,48 & 0,50 & 319,36 & 18,10 & 558,96 & 31,70 & 875,19 & 49,70 \\
\hline $\mathrm{C}$ & 33,14 & 2,11 & 338,61 & 21,57 & 752,51 & 47,94 & 445,46 & 28,38 \\
\hline D & 318,88 & 17,30 & 585,98 & 31,80 & 855,07 & 46,50 & 80,19 & 4,40 \\
\hline
\end{tabular}


Com relação ao uso e cobertura dos solos na bacia pode-se observar na Figura 4, que na sub-bacia A, a presença de maior área de pastagens $(69,4 \%)$ e florestas $(25,7 \%)$ em local próximo ás nascente dos cursos d'água que formam o ribeirão Itaim. Na sub-bacia $\mathrm{B}$, a maior área é também de pastagens $(74,4 \%)$, e florestas $(20,8 \%)$.

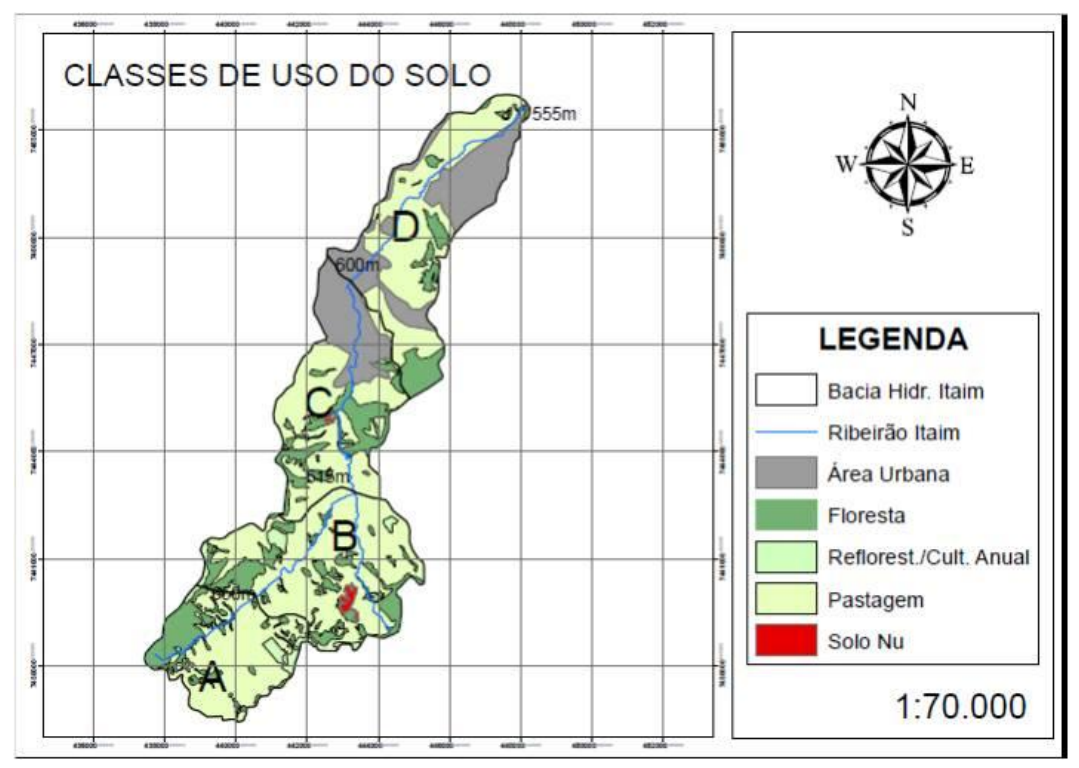

Figura 4. Mapa de classes de uso e cobertura do solo na bacia do ribeirão Itaim.

$\mathrm{Na}$ sub-bacia $\mathrm{C}$ ocorre a presença de área de pastagens $(54,1 \%)$, e florestas esparsas $(19,7 \%)$, mas também se observa uma mancha urbana da ordem de $(25,9 \%)$ e na sub-bacia D, ocorre a presença de pastagens $(53,6 \%)$, e com pequenas manchas de florestas $(11,7 \%)$, e uma mancha urbana $(34,7 \%)$ próxima a foz do ribeirão Itaim.

O tipo hidrológico do solo $\mathrm{C}$ (Tabela 1) e as áreas de uso e ocupação dos solos de cada sub-bacia (Tabela 2), são importantes para a obtenção de um valor representativo de $\mathrm{CN}$ foram utilizados como base para definir valores de $\mathrm{CN}$ ponderado para cada sub-bacia, a partir dos dados de Setzer e Porto (1979).

Tabela 2. Valores de CN e área das classes de uso e ocupação do solo para as sub-bacias A, B, C e D.

\begin{tabular}{ccccccccccc}
\hline $\begin{array}{c}\text { Sub } \\
\text { Bacia }\end{array}$ & $\begin{array}{c}\text { Floresta } \\
\text { (ha) }\end{array}$ & CN & $\begin{array}{c}\text { Reflorestamento } \\
\text { (ha) }\end{array}$ & CN & $\begin{array}{c}\text { Pasto } \\
\text { (ha) }\end{array}$ & CN & $\begin{array}{c}\text { Solo nú } \\
\text { (ha) }\end{array}$ & $\begin{array}{c}\text { CN } \\
\text { Urbana } \\
\text { (ha) }\end{array}$ & CN \\
\hline A & 279,37 & 55 & 53,54 & 62 & 755,95 & 75 & ------ & --- & ------- & --- \\
B & 366,17 & 55 & 61,53 & 62 & 1310,34 & 75 & 23,98 & 88 & ------- & --- \\
C & 308,75 & 55 & ------ & --- & 850,00 & 75 & 5,07 & 88 & 405,90 & 90 \\
D & 215,66 & 55 & ------ & --- & 986,54 & 75 & ------ & --- & 637,92 & 90 \\
\hline
\end{tabular}

A partir dos dados de $\mathrm{CN}$ definidos na Tabela 2 foi obtido o $\mathrm{CN}$ ponderado por meio da Equação 3 e dessa forma para as sub bacias A, B, C e D os valores encontrados foram respectivamente 69,$23 ; 70,57 ; 74,99$ e 77,86. Esses resultados indicam que na Bacia A e B deve ocorrer maior infiltração devido a ocorrência de maior concentração de florestas, eucalipto e Pasto, enquanto nas sub-bacias C e D a maior presença de áreas urbanas deve reduzir o valor da infiltração.

Por meio da Equação 6 com o intervalo de curvas de nível de 20 em 20 metros foi calculada a a declividade equivalente, a qual foi utilizada na Equação 5, para calcular o 
Tempo de concentração de 47,4; 82,5; 220,6 e 140,2 minutos, respectivamente, para as subbacias A, B, C e D.

A partir desses resultados e igualando-se o Tc ao tempo de duração da precipitação foram calculados para cada sub-bacia a precipitação máxima para o tempo de retorno de 100 anos, por meio da Equação de precipitações máximas da cidade de Taubaté, SP (Equação 7) de Martinez Junior e Magni (1999). Os resultados das Precipitações efetivas (Pe) e das Infiltrações potenciais (S) obtidas pelo método Curva Número (USDA, 2010), bem como, os coeficientes de escoamento superficial volumétrico $\left(\mathrm{C}_{2}\right)$ para cada sub-bacia são demonstrados na Tabela 3.

Tabela 3. Valores de Precipitação efetiva (Pe), Infiltração potencial (S) e coeficiente de escoamento (C) para cada sub bacia.

\begin{tabular}{ccccccc}
\hline Sub-bacia & $\begin{array}{c}\mathrm{Td} \\
(\mathrm{min})\end{array}$ & $\begin{array}{c}\mathrm{CN} \\
\text { ponderado }\end{array}$ & $\begin{array}{c}\mathrm{S} \\
(\mathrm{mm})\end{array}$ & $\begin{array}{c}\mathrm{P} \\
(\mathrm{mm})\end{array}$ & $\begin{array}{c}\mathrm{Pe} \\
(\mathrm{mm})\end{array}$ & $\mathrm{C}_{2}$ \\
\hline ABCD & 344 & 73,58 & 91,23 & 125,26 & 57,78 & 0,38 \\
A & 47,4 & 69,23 & 112,90 & 79,54 & 19,10 & 0,24 \\
B & 82,5 & 70,57 & 105,94 & 95,49 & 30,63 & 0,32 \\
C & 220,6 & 74,99 & 84,73 & 117,65 & 54,69 & 0,46 \\
D & 140,2 & 77,86 & 72,24 & 108,45 & 53,15 & 0,49 \\
\hline
\end{tabular}

Para a utilização do método I-PAI-WU de cálculo de vazões máximas foi utilizada a Equação 8, os Coeficientes de escoamento superficial (C) foram calculados a partir das equações 9,10 e 11. Os valores de coeficiente volumétrico $\left(\mathrm{C}_{2}\right)$ em função do grau de impermeabilização da superfície do solo de cada sub-bacia foi obtido a partir do método Curva Número, por meio da Equação 4. Os resultados dos coeficientes encontram-se na Tabela 4.

Tabela 4. Coeficientes utilizados no cálculo da vazão pelo método I PAI WU para cada sub bacia.

\begin{tabular}{ccccc}
\hline Sub-bacias & $\mathrm{F}$ & $\mathrm{C}_{1}$ & $\mathrm{C}_{2}$ & $\mathrm{C}$ \\
\hline ABCD & 2,68 & 0,85 & 0,38 & 0,24 \\
A & 1,02 & 1,32 & 0,24 & 0,18 \\
B & 1,03 & 1,32 & 0,32 & 0,24 \\
C & 1,68 & 1,09 & 0,46 & 0,32 \\
D & 1,60 & 1,11 & 0,49 & 0,34 \\
\hline
\end{tabular}

Além dos coeficientes da Tabela 4, os parâmetros necessários e o cálculo da vazão máxima produzida por uma precipitação com 100 anos de Tempo de retorno e duração igual ao Tempo de concentração de cada sub-bacia a partir da Equação 7 estão demonstrados na Tabela 5. Conforme se pode observar embora com menor declividade e intensidade de precipitação se produza menores valores de vazão máxima, mesmo em situações como as subbacias C e D que apresentam maior grau de urbanização. 
Tabela 5. Parâmetros necessários para o cálculo da vazão máxima para cada sub bacia.

\begin{tabular}{|c|c|c|c|c|c|c|c|c|}
\hline TR & Sub Poni & Área & Cmp_Tlv & $\mathrm{C}$ & Decl_BH & Tmp.cnc & I_Max & Vaz_Max \\
\hline Anos & S40 & $\left(\mathrm{km}^{2}\right)$ & (m) & $(\mathrm{adm})$ & $(\mathrm{m} / \mathrm{km})$ & $(\min )$ & $(\mathrm{mm} / \mathrm{h})$ & $\left(\mathrm{m}^{3} / \mathrm{s}\right)$ \\
\hline \multirow{5}{*}{100} & $\mathrm{ABCD}$ & 62,61 & 23956 & 0,24 & 5,41 & 364,37 & 20,78 & 57,19 \\
\hline & A & 10,89 & 3805 & 0,18 & 23,42 & 47,40 & 100,73 & 42,64 \\
\hline & B & 17,62 & 4877 & 0,24 & 9,10 & 82,50 & 69,45 & 60,38 \\
\hline & $\mathrm{C}$ & 15,70 & 7521 & 0,32 & 1,99 & 220,60 & 32,00 & 33,15 \\
\hline & D & 18,40 & 7753 & 0,34 & 5,80 & 140,20 & 46,41 & 59,58 \\
\hline
\end{tabular}

A partir de dados de curvas de nível da bacia do Itaim (Batista et al., 2005) foi possível definir a área entre as curvas de nível e em função das diferenças entre as curvas foi possível calcular o volume de água acumulado entre as mesmas e construir as curvas cota-volume para cada barramento. As Figuras 5 e 6 mostram as áreas inundadas entre as curvas de nível e as Figuras 7 e 8 mostram os hidrogramas triangulares sintéticos para cada sub-bacias.

Os volumes de entrada e saída forma calculados partir da construção de hidrogramas de cheia simplificados em forma triangular (DAEE, 2008). O Volume de entrada foi calculado a partir da vazão máxima produzida por cada uma das sub-bacias como reação ao evento de chuva de 100 anos de tempo de retorno, e, o volume de saída, calculado a partir da adoção da vazão $\left(8,12 \mathrm{~m}^{3} / \mathrm{s}\right)$ correspondente ao momento em que a água atinge 2,5 metros e sai da calha do ribeirão Itaim. Nessa metodologia o tempo de base do hidrograma triangular é correspondente a 3Tc. A bacia do Itaim (ABCD) apresenta em sua maior concentração o uso e cobertura do solo predominante é pastagem (62\%) concentrada em Argissolo vermelho amarelo (2166 ha) e Cambissolo háplico (1400 ha). Apresenta um coeficiente de escoamento $(\mathrm{C}=0,24)$ e declividade do ribeirão considerada baixa $(5,41 \mathrm{~m} / \mathrm{km})$, de forma que o escoamento atinge o exutório da bacia em um tempo ao redor de 364 minutos.

Considerando os volumes calculados por meio do hidrograma correspondente (Figura 8) com vazão de entrada $\left(57,19 \mathrm{~m}^{3} / \mathrm{s}\right)$ e de saída $(8,12 \mathrm{~m} / \mathrm{s})$, o volume resultante é $1.609 .047 \mathrm{~m}^{3}$, por meio da curva cota-volume (Figura 9), o volume de inundação atingiria a cota de inundação de $559,8 \mathrm{~m}$. No levantamento georreferenciado a cota da ponte na rodovia Professor Dr. José Luiz Cembranelli é 559,378 m e nessa situação a água passaria por cima da rodovia. É de se notar que essa inundação ainda não ocorreu na bacia do ribeirão Itaim.

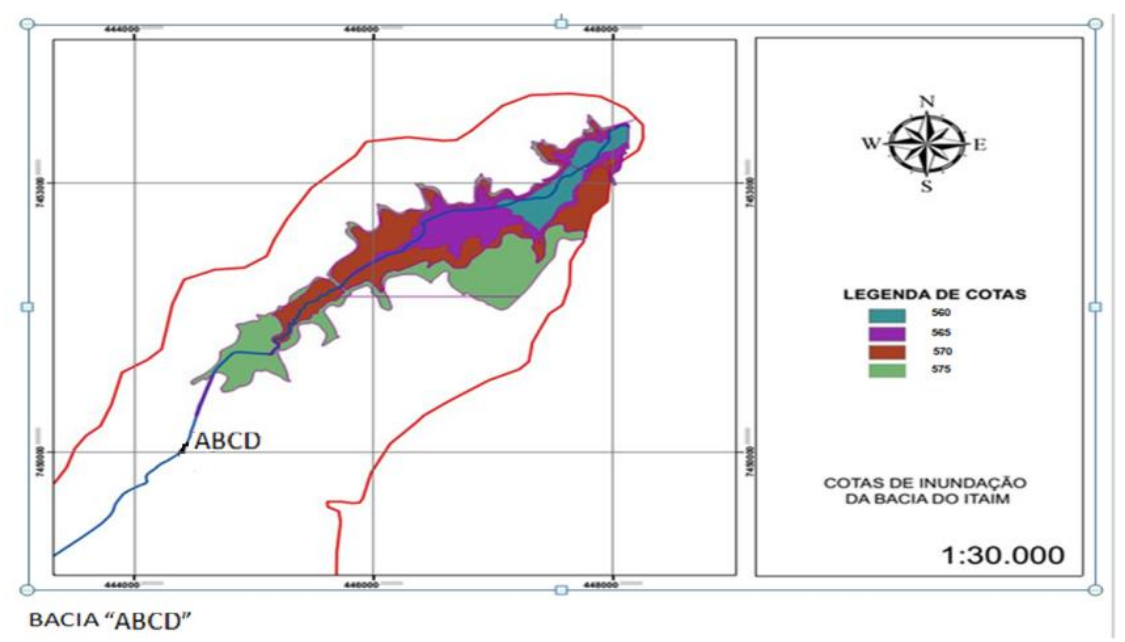

Figura 5. Mapa das cotas de Inundação da bacia Hidrográfica ABCD. 


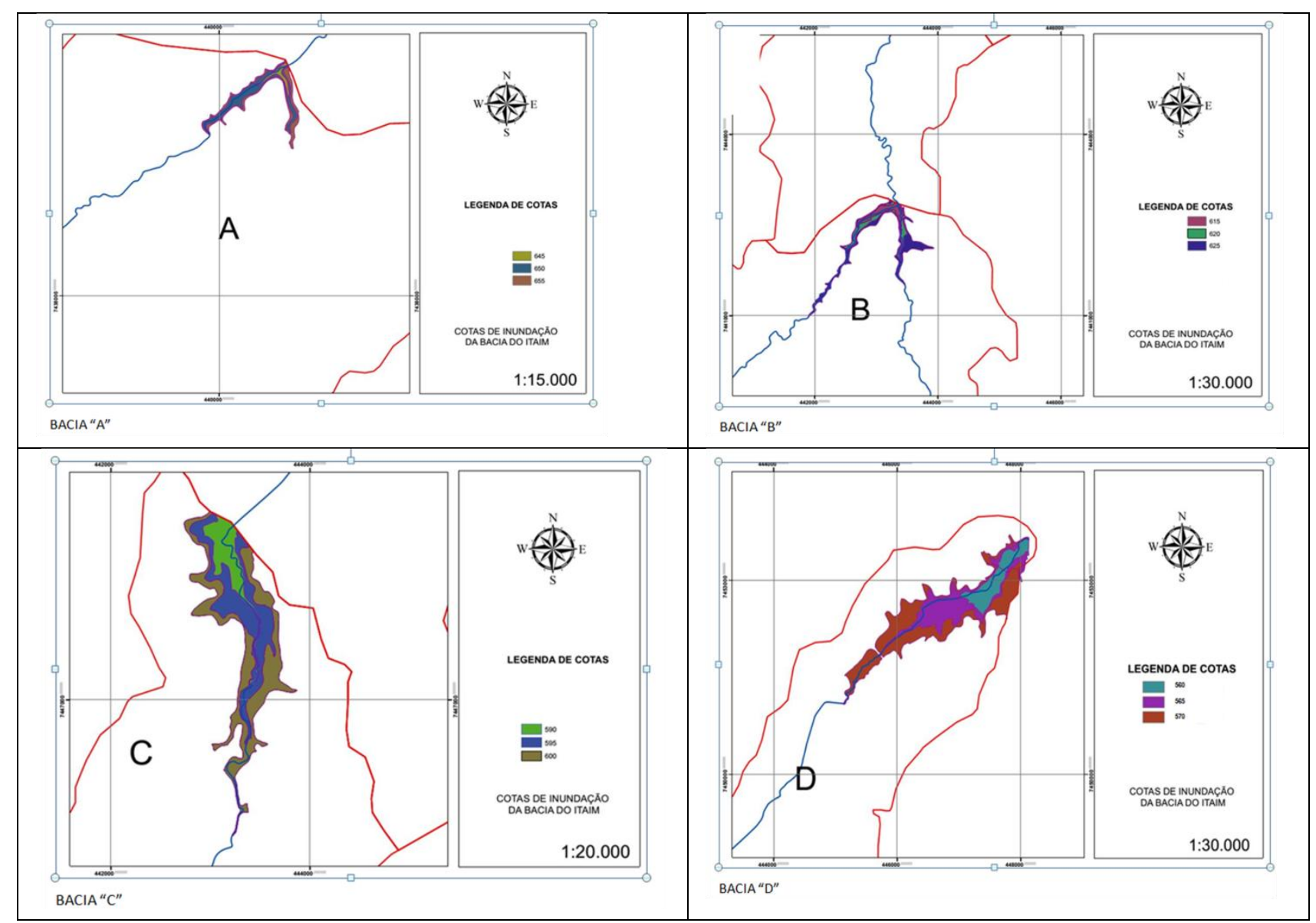

Figura 6. Mapa das cotas de inundação das sub-bacias A, B, C e D.

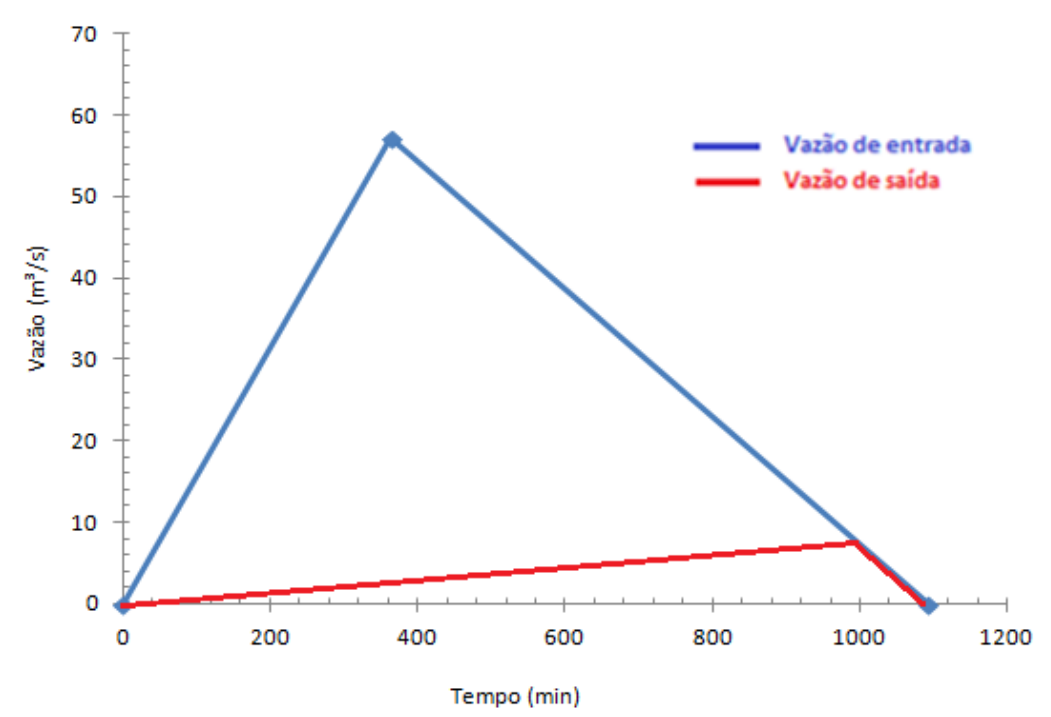

Figura 7. Hidrograma triangular sintético para o escoamento produzido por uma precipitação de 100 anos de retorno na bacia do ribeirão Itaim. 


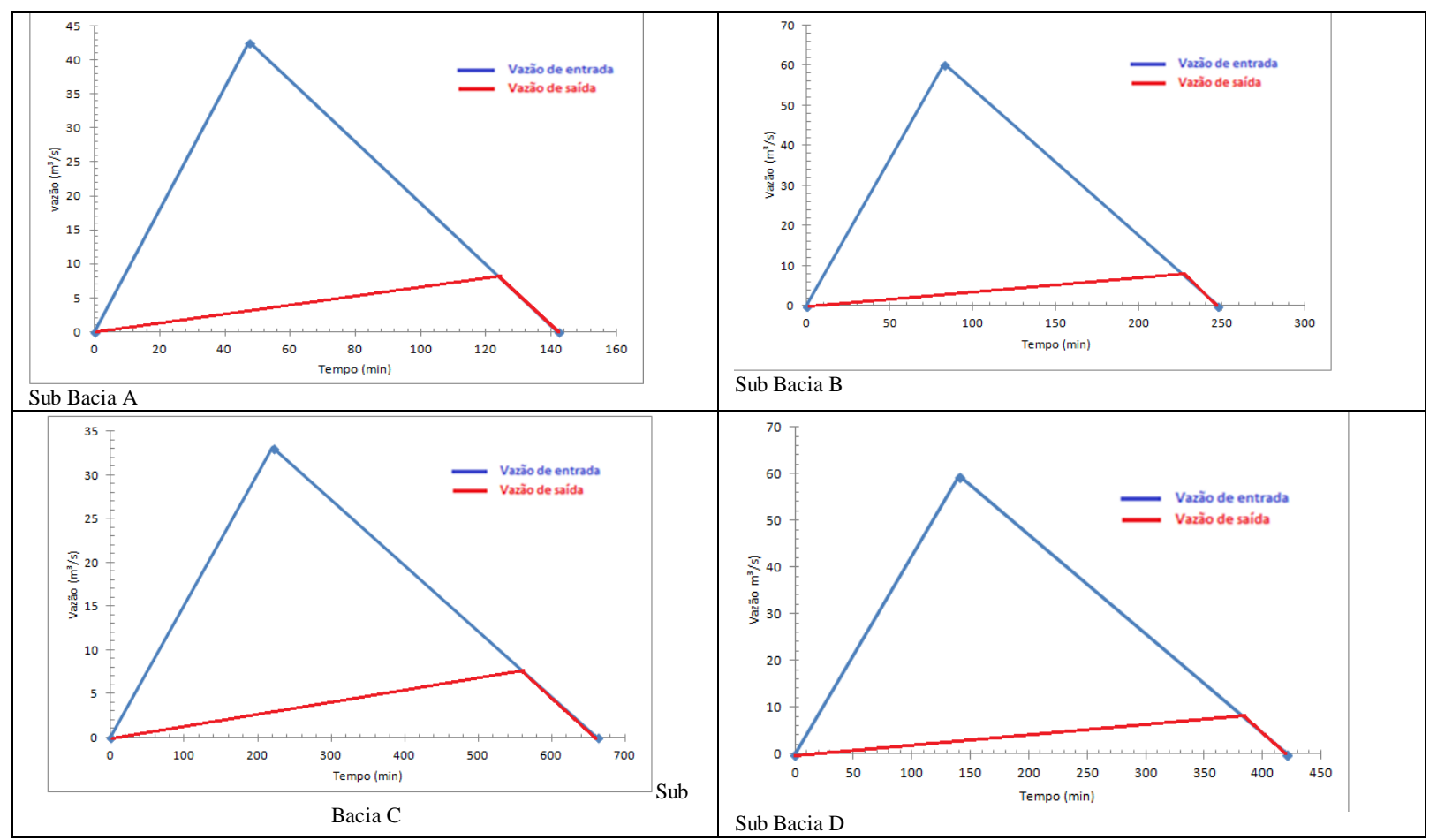

Figura 8. Hidrogramas triangulares sintéticos para o escoamento produzido para cada sub-bacia do ribeirão Itaim.

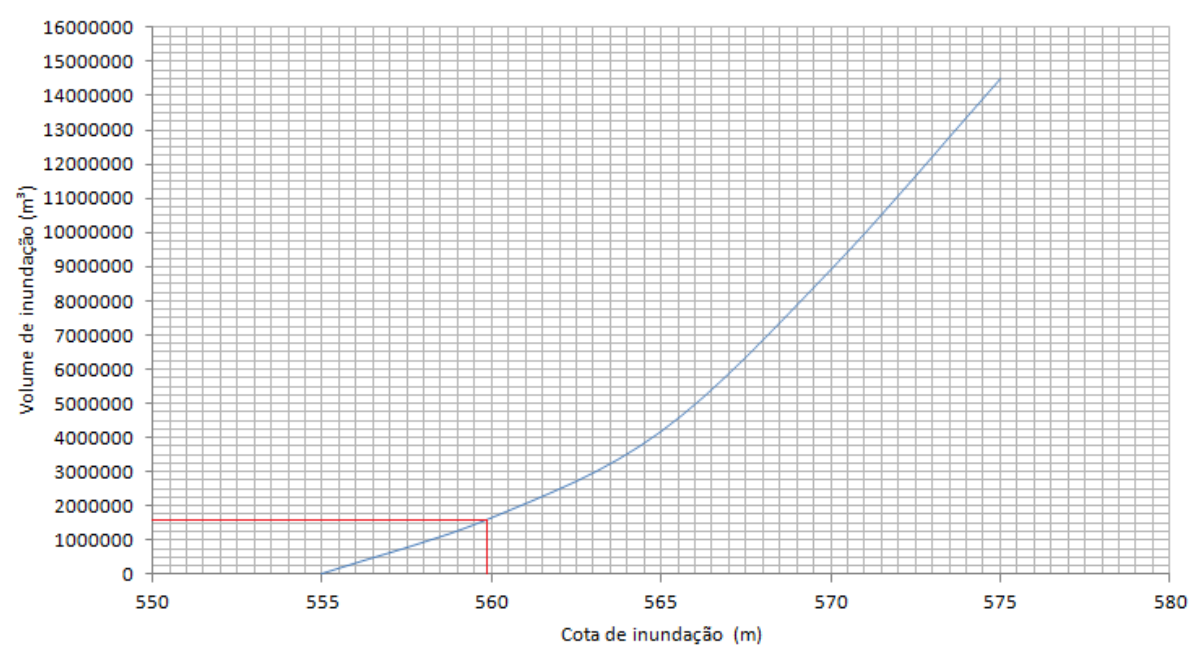

Figura 9. Cota de inundação atingida na curva cota-volume para o escoamento produzido por uma precipitação de 100 anos de retorno na bacia do ribeirão Itaim.

Observando a sub-bacia A possui as áreas mais elevadas da bacia onde o uso e cobertura do solo predominante é pastagem (711 ha) concentrada em Cambissolo háplico (972 ha), apresenta um coeficiente de escoamento $(C=0,18)$ e declividade do ribeirão elevada $(23,42 \mathrm{~m} / \mathrm{km})$, de forma que o escoamento atinge o barramento em um tempo ao redor de 47 minutos. Considerando os volumes calculados por meio do hidrograma correspondente (Figura 8) com vazão de entrada $\left(42,64 \mathrm{~m}^{3} / \mathrm{s}\right)$ e de saída $\left(8,12 \mathrm{~m}^{3} / \mathrm{s}\right)$, o volume resultante é $147.150 \mathrm{~m}^{3}$, por meio da curva cota-volume (Figura 10), o volume de inundação atingiria (Tabela 6) a cota de inundação em 646,8 m. 
A sub-bacia B apresenta-se com as áreas de média elevação na bacia, o uso e cobertura do solo predominante é pastagem (1310 ha) que se concentra em Cambissolo háplico $(875,19$ ha), apresenta um coeficiente de escoamento $C(0,24)$ e declividade média do ribeirão de $(9,10 \mathrm{~m} / \mathrm{km})$, de forma que o escoamento atinge o barramento em um tempo ao redor de 83 minutos. Considerando os volumes calculados por meio do hidrograma correspondente (Figura 8) com vazão de entrada $\left(60,38 \mathrm{~m}^{3} / \mathrm{s}\right)$ e de saída $\left(8,12 \mathrm{~m}^{3} / \mathrm{s}\right)$ o volume resultante de $388.054 \mathrm{~m}^{3}$, por meio da curva cota-volume (Figura 10), o volume acumulado no barramento atingiria (Tabela 6) a cota de inundação de 614,9 m.

A sub-bacia $\mathrm{C}$ concentra as áreas mais baixas da bacia do Itaim e o uso e cobertura do solo predominante é pastagem (850 ha) em Argissolo vermelho amarelo (752 ha) e apresenta um coeficiente de escoamento superficial $(C=0,32)$ e declividade equivalente do Ribeirão Itaim de $1,99 \mathrm{~m} / \mathrm{km}$, de forma que o escoamento atinge o barramento em um tempo ao redor de 220 minutos. Considerando os volumes calculados por meio do hidrograma correspondente (Figura 8) com vazão de entrada $\left(33,15 \mathrm{~m}^{3} / \mathrm{s}\right)$ e de saída $\left(8,12 \mathrm{~m}^{3} / \mathrm{s}\right)$, o volume resultante é $496.943 \mathrm{~m}^{3}$, por meio da curva cota-volume (Figura 10), o volume de inundação (Tabela 6) atingiria a cota de inundação de 587,8 m.

A sub-bacia D concentra áreas baixas na bacia do Itaim e o uso e cobertura do solo predominante é pastagem (986 ha) concentrada em Argissolo vermelho amarelo (855 ha) e apresenta um coeficiente de escoamento $(C=0,34)$ e declividade baixa $(5,80 \mathrm{~m} / \mathrm{km})$ do ribeirão, de forma que o escoamento atinge o barramento em um tempo ao redor de 140 minutos.

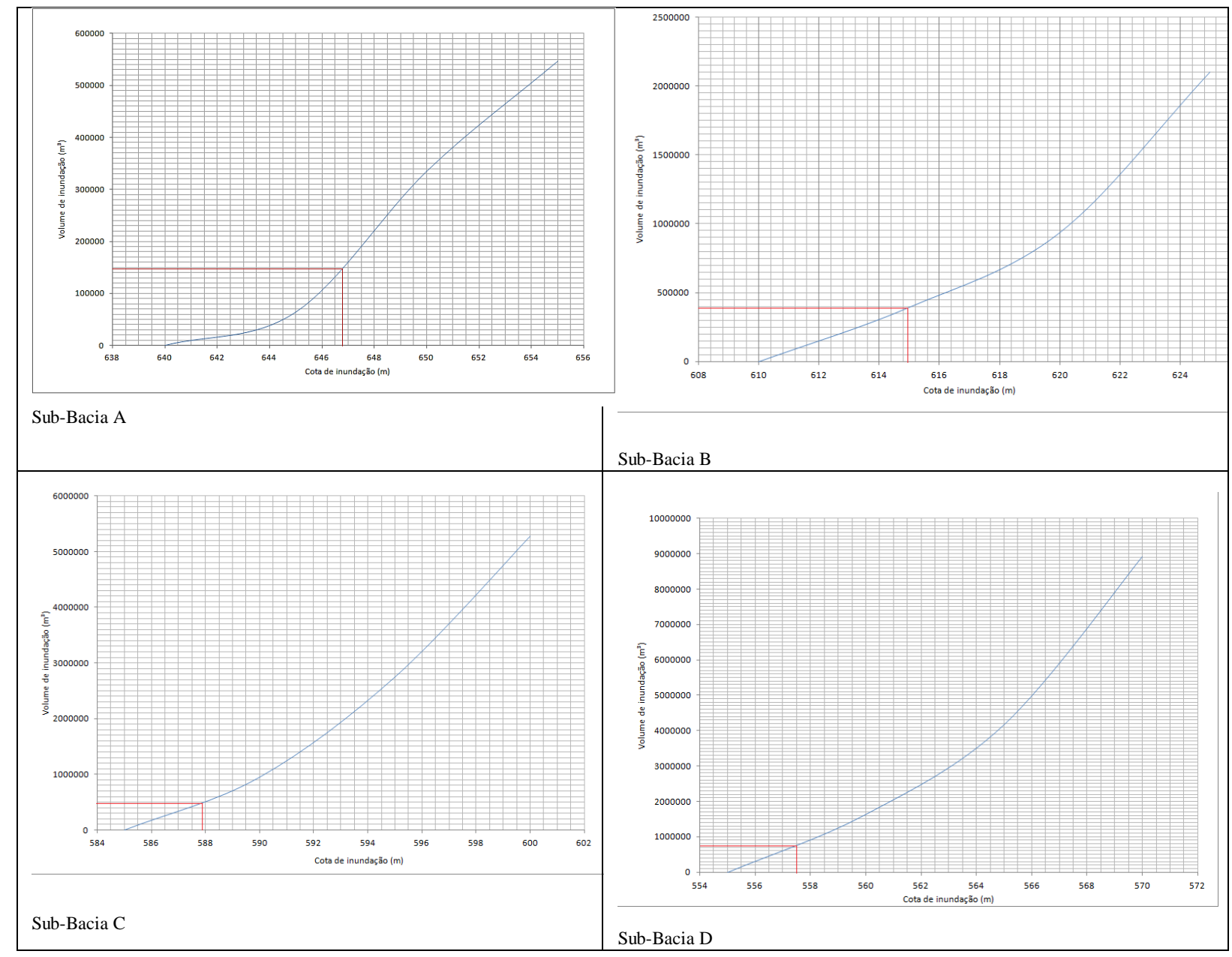

Figura 10. Cota de inundação atingida na curva cota-volume para o escoamento produzido por uma precipitação de 100 anos de retorno para cada sub-bacia do ribeirão Itaim. 
Tabela 6. Vazões de entrada e saída e volumes acumulados em cada barramento nas sub bacias.

\begin{tabular}{ccccc}
\hline Sub-Bacia & $\begin{array}{c}\text { Ve } \\
\left(\mathrm{m}^{3}\right)\end{array}$ & $\begin{array}{c}\text { Vs } \\
\left(\mathrm{m}^{3}\right)\end{array}$ & $\begin{array}{c}\mathrm{Vr} \\
\left(\mathrm{m}^{3}\right)\end{array}$ & Cota de inundação $(\mathrm{m})$ \\
\hline ABCD & 1.875 .329 & 266.281 & 1.609 .047 & 559,8 \\
A & 181.764 & 34.614 & 147.150 & 646,8 \\
B & 448.354 & 60.300 & 388.054 & 614,9 \\
C & 658.183 & 161.240 & 496.943 & 587,8 \\
D & 751.735 & 102.453 & 649.282 & 557,5 \\
\hline
\end{tabular}

Considerando os volumes calculados por meio do hidrograma correspondente (Figura 8) com vazão de entrada $\left(59,58 \mathrm{~m}^{3} / \mathrm{s}\right)$ e de saída $\left(8,12 \mathrm{~m}^{3} / \mathrm{s}\right)$, o volume resultante é $649.282 \mathrm{~m}^{3}$, por meio da curva cota-volume (Figura 10) o volume de inundação (Tabela 6) atingiria a cota de inundação de $557,5 \mathrm{~m}$.

O objetivo da retenção em bacias ou barramentos é reter o escoamento e evitar problemas de inundação. Evidentemente que o uso e ocupação dos solos de uma bacia é um processo dinâmico e que a precipitação máxima com 100 anos de tempo de retorno ainda não ocorreu na bacia. Considerando a cotas da ponte sob a rodovia Professor Dr. José Luiz Cembranelli no ribeirão Itaim $(559,38 \mathrm{~m})$ comparativamente ao obtido no barramento da sub-bacia $\mathrm{D}$ na mesma ponte, e como o volume resultante do escoamento proveniente de uma precipitação máxima com período de retorno da ordem de 100 anos na bacia do Itaim, alcançaria a cota de $557,5 \mathrm{~m}$, não passaria por cima da rodovia e na realidade manteria uma folga de $1,88 \mathrm{~m}$.

\section{CONCLUSÃO}

É possível controlar o escoamento superficial por meio da construção de barragens de detenção;

O método da curva cota-volume funciona adequadamente e demonstrou que na bacia do ribeirão Itaim, as barragens de detenção são capazes de frear a cheia não permitindo causar inundação.

O método do hidrograma triangular sintético demonstrou ser de fácil utilização.

\section{REFERÊNCIAS}

AGUIAR, L. S. G.; TARGA, M. S.; BATISTA, G. T. Escoamento superficial na bacia hidrográfica do Ribeirão Itaim. Revista Ambiente \& Água, v. 2, n. 1, p. 44-56, 2007. http://dx.doi.org/10.4136/ambi-agua.19.

ANACletO, L. M. O; RODRIGUES, A. B.; SOUZA, G. T. A. M.; BARBOSA, N. R.; DIAS, V.; TARGA, M. S. Hidrógrafa unitária conservacionista em bacias hidrográficas. 2015. p. 1-16. Disponível em: http://agro.unitau.br/dspace. Acesso em: dez 2016.

BATISTA, G. T.; TARGA, M. S.; DIAS, N. W.; CATELANI, C. S. Modelo de banco de dados ambientais georreferenciados voltado à recuperação e preservação de recursos hídricos de uma bacia de médio porte, o modelo da bacia do rio Una, Paraíba do Sul, SP. In: SIMPÓSIO BRASILEIRO DE RECURSOS HÍDRICOS (SBRH), 16., 2005, João Pessoa. Anais... Rio de Janeiro: ABRH, 2005. v. 1. p. 1-16.

BRASIL. Presidência da República. Casa Civil. Lei 12.651 de 25 de maio de 2012. Diário Oficial [da] União, Brasília, 28 maio 2012. 
CALZETTA, B.; TARGA, M.S. Uso e ocupação do solo na microbacia do Itaim - Taubaté, SP. Revista biociências, v. 9, n. 3, p. 39-48, 2003.

CORRÊA, R. C. Avaliação das atividades antrópicas sobre a bacia hidrográfica do ribeirão Itaim - Taubaté - SP. 2001. 108 f. Dissertação (Mestrado em Ciências Ambientais) - Universidade de Taubaté, Taubaté, 2001.

DEPARTAMENTO DE ÁGUA E ENERGIA ELÉTRICA - DAEE (São Paulo). Guia prático para projetos de pequenas obras hidráulicas. São Paulo, 2008.

FISCH, F. G. Caracterização climática e balanço hídrico de Taubaté (SP) Universidade de Taubaté. Revista Biociências, v. 5, n. 2, 1999.

GOOGLE EARTH. Google Earth Pro 7.1. 2014.

INSTITUTO BRASILEIRO DE GEOGRAFIA E ESTATÍSTICA - IBGE. Carta do Brasil. 1:50.000. Rio de Janeiro, 1973. Disponível em: ftp://geoftp.ibge.gov.br/cartas_e_mapas/folhas_topograficas/editoradas/escala_50mil/ta ubate27692.pdf. Acesso em: $\operatorname{dez} 2016$.

LOBATO, A. A.; TARGA, M. S. Levantamento do uso e das condições de conservação da água na Bacia hidrográfica do ribeirão Itaim no município de Taubaté- SP. Revista Biociências, v. 4, n. 4, 2004.

MARTINEZ JUNIOR, F.; MAGNI, N. L. G. Equações de chuvas intensas do Estado de São Paulo. São Paulo: Departamento de Águas e Energia Elétrica; Universidade de São Paulo, 1999. 125 p.

MELO, W. L. S.; BATISTA, G. T.; TARGA, M. S.; RODRIGUES, N. D. Análise Comparativa do Uso do Solo e Estimativa do Escoamento Superficial com Base na Capacidade de Infilttração da Bacia Hidrográfica do Itaim, Taubaté, SP. In: SIMPÓSIO BRASILEIRO DE RECURSOS HÍDRICOS, 19., 2011, Maceió. Programa Final. Porto Alegre: SBRH, 2011. v. 1.

MOREIRA, D. W.; TARGA, M. S.; BATISTA, G. T. Relações entre chuvas intensas, vazões máximas e sedimentação do ribeirão Itaim, Taubaté, SP. Revista Biociências, v. 12, n. $1-2,2006$.

PERIM, M. A.; SANTOS, E. R.; LEITE, C. R. S.; GONÇALVES, S. F.; TARGA, M. S. Hidrograma unitário e urbanização em bacia hidrográfica. 2015. p. 1-13. Disponível em: http://www.agro.unitua.br/dspace. Acesso em dez 2016.

SARTORI, A.; LOMBARDI NETO, F.; GENOVEZ, A. M. Classificação hidrológica de solos brasileiros para estimativa da chuva excedente com o método do Serviço de Conservação do Solo dos Estados Unidos Parte 1: Classificação. Revista Brasileira de Recursos Hídricos, v. 10, n. 4, p. 05-18, 2005.

SBRUZZI, R. S. Metodologia para verificação da adequação do uso da terra na bacia do ribeirão Itaim, afluente do rio Uma, Taubaté, SP. 2004. 75 f. Dissertação (Mestrado em Ciências Ambientais) - Departamento de Ciências Agrárias, Universidade de Taubaté, Taubaté, 2004.

SETZER, J.; PORTO, R. L. L. Tentativa de avaliação do escoamento superficial de acordo com o solo e o seu recobrimento vegetal nas condições do estado de São Paulo. Boletim Técnico - DAEE, v. 2, n. 2, 1979. 
TARGA, M. S.; BATISTA, G. T.; CÍCERO, C. M.; DIAS, N. W. Metodologia para avaliação dos processos hidrológicos e da sedimentação na bacia hidrográfica experimental do Ribeirão Itaim, município de Taubaté, no Vale do Paraíba do $\underline{\text { Sul }}$ - Estado de São Paulo. 2006. Disponível em: http://hdl.handle.net/2315/54. Acesso em: dez 2016.

TARGA, M. S. Vazão de projeto em bacias hidrográficas rurais com áreas em declive. 2011. p. 1-20. Disponível em: http://www.agro.unitau.br/dspace. Acesso em: dez. 2016.

TUCCI, C. E. M. Coeficiente de escoamento e vazão máxima de bacias urbanas. Revista Brasileira de Recursos Hídricos, v. 5, n. 1, p. 61-68, 2000.

UNITED STATES. Department of Agriculture. Natural Resources Conservation Service. Estimation of Direct Runoff from Storm Raifall. In: National Engineering Handbooks Hydrology. Washington, 1997. Part 630. Cap. 10. 79 p. Disponível em: http://www.ftw.nrcs.usda.gov. Acesso em: abril 2010. 